Revista Bioética

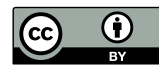

Print version ISSN 1983-8042 On-line version ISSN 1983-8034

Rev. Bioét. vol.28 no.3 Brasília Jul./Set. 2020

Doi: 10.1590/1983-80422020283408

\title{
ATUALIZAÇÃO
}

\section{Justiça, cuidado e reconhecimento: trama moral do vínculo terapêutico}

Pablo Dias Fortes ${ }^{1}$, Sergio Rego ${ }^{1}$

1. Departamento de Ciências Sociais, Escola Nacional de Saúde Pública, Fundação Oswaldo Cruz, Rio de Janeiro/RJ, Brasil.

\section{Resumo}

O objetivo deste ensaio, dividido em duas partes, é investigar a estrutura geral do vínculo terapêutico. A primeira parte descreve agentes sociais como sujeitos moralmente interpelados pela norma fundamental da justiça ("a cada qual o que lhe é devido"), que na cena particular do cuidado se desdobra em potenciais conflitos intersubjetivos. A segunda representa a relação terapêutica articulada com os "três níveis do juízo médico" apontados por Paul Ricoeur - prudencial, deontológico e reflexivo -, conferindo às prescrições desse âmbito o estatuto de relação francamente moral.

Palavras-chave: Ética médica. Status moral. Justiça social. Relações médico-paciente.

\section{Resumen}

\section{Justicia, cuidado y reconocimiento: trama moral del vínculo terapéutico}

El objetivo de este ensayo, que se divide en dos partes, es investigar la estructura general del vínculo terapéutico. La primera parte describe a los agentes sociales como sujetos a los que la norma fundamental de la justicia ("a cada uno lo suyo") interpela moralmente, lo que, en la escena particular de la atención médica, se desdobla en posibles conflictos intersubjetivos. La segunda parte muestra la relación terapéutica que se articula mediante lo que el filósofo Paul Ricoeur denomina "los tres niveles de juicio médico" -prudencial, deontológico y reflexivo-, confiriendo a las prescripciones de este ámbito el estatuto de una relación francamente moral.

Palabras clave: Ética médica. Condición moral. Justicia social. Relaciones médico-paciente.

\begin{abstract}
Justice, care and recognition: the moral fabric of therapeutic bonds

This article investigates the general structure of the therapeutic bond in two parts: a pragmatic description of social agents as subjects morally challenged by the fundamental norm of justice ("to each one what is due"), which in healthcare may also have potential intersubjective conflicts; and a representation of the therapeutic relationship based on Paul Ricœur's "three levels of medical judgment" (prudential, deontological and reflexive), giving the prescriptions in this scope the status of a moral relationship.

Keywords: Ethics, medical. Moral status. Social justice. Physician-patient relations.
\end{abstract}

Declaram não haver conflito de interesse. 
As relações entre justiça e saúde costumam ser interpretadas como problema distributivo concernente à extensão e à regulação do direito ao cuidado médico. Assim, questões como "acesso aos serviços", "alocação de recursos" e "políticas de promoção da equidade" ganham visibilidade na medida em que mobilizam ideias e conceitos das chamadas "teorias da justiça", com seu foco explícito nos fundamentos normativos da sociedade. Embora sem ignorar essas abordagens, este ensaio pretende destacar outra dimensão dessa relação, investigando a estrutura do vínculo terapêutico.

Primeiro, o texto propõe descrição pragmática dos agentes sociais como sujeitos moralmente interpelados pela norma fundamental da justiça ("a cada qual o que lhe é devido"), que na cena particular do cuidado se desdobra em potenciais conflitos intersubjetivos. Em segundo momento, representa-se a relação terapêutica articulada com os "três níveis do juízo médico" apontados por Ricoeur ${ }^{1}$ - prudencial, deontológico e reflexivo -, conferindo às prescrições desse âmbito o estatuto de relação francamente moral.

\section{Agente social como sujeito moral}

Muitas teorias já foram produzidas com o fim de elucidar o significado da ação social em conformidade com a coordenação recíproca das ações, que marca, do ponto de vista pragmático, a vida em sociedade ${ }^{2-5}$. O indivíduo que age "socialmente", portanto, é aquele que já se reconhece na condição simbólica de sujeito - do latim subjectum: "lançado embaixo", "o que está submetido" 6 . Ele é compelido a estabelecer consigo relação prática de causalidade que define a experiência de si mesmo (autoconsciência) como função primordial das atividades interativas.

Nesse sentido, a noção de que o êxito das interações (a coordenação recíproca das ações) depende do tácito entendimento entre indivíduos acerca do que é devido a cada qual surge como corolário inevitável da autoconsciência ${ }^{7}$. Daí que o sentido das ações envolva também a experiência da própria integridade subjetiva.

A ideia de que as relações (com outros e com nós mesmos) implicam a dinâmica moralmente centrada nas expectativas de reconhecimento recíproco tem sido a base de modelos de análise que decodificam processos interativos em diferentes circunstâncias e espaços da vida em sociedade. Assim, a noção de que o valor atribuído à nossa própria identidade pessoal decorre da estrutura intersubjetiva - da qual ela se desdobra como experiência social assimilada ${ }^{8-10}$ - é importante eixo para compreender a natureza do vínculo interpessoal, as motivações que nos levam a agir dessa ou daquela maneira e os conflitos intersubjetivos que daí decorrem.

Visto sob tal prisma, o nexo entre "justiça" e "reconhecimento" indica incontornável perspectiva analítica para examinar as práticas sociais, em especial quando se tem em mente situações conflagradas por relações de profunda heteronomia entre os agentes ${ }^{11}$. Em tais circunstâncias, a expectativa de que as interações se desenvolvam com base no reconhecimento recíproco costuma dar lugar a impasses insolúveis, condenando as relações a tipo de violência que atinge em cheio a promessa de autorrealização que caracteriza o indivíduo como agente social.

Com base nesse argumento, admite-se que a estrutura das relações terapêuticas, estabelecida sobre um pacto de tratamento ${ }^{12}$, está igualmente fundada em demanda de reciprocidade: ambas as partes (pacientes e profissionais de saúde) esperam ser reconhecidas para além da dimensão puramente técnica e objetiva da gestão do cuidado. No fundo, trata-se de relação cuja assimetria constitutiva (discurso leigo versus discurso técnico) impõe desafios, a começar pelo modo como a parte mais vulnerável - o paciente - acaba por representar a si mesma na esperança de evitar sofrer ainda mais com protocolos assistenciais (anamneses, inquéritos, registros, notificações etc.) convertidos em julgamentos condenatórios de sua história de vida. Tais julgamentos arruínam a possibilidade de um laço de confiança que gere compromisso autêntico em torno das opções terapêuticas disponíveis.

Nesse contexto, é oportuno destacar a tese desenvolvida pela filósofa Judith Butler ${ }^{10}$ de que obrigações e deveres que nos ligam socialmente nem sempre são redutíveis a atos de juízo. De tal modo, estabelecer campo comum de responsabilidades exige muitas vezes a suspensão do julgamento. Mais uma vez, insinua-se aí a estrutura de uma relação em que o problema de saber o que é "devido a cada qual" é mutuamente implicativo. Múltiplas expectativas terminam por se confrontar com a necessidade de reajustar radicalmente os termos éticos da relação. Como bem observa Butler:

Talvez somente pela experiência do outro, sob a condição de termos suspendido o juízo, tornamo-nos finalmente capazes de uma reflexão ética sobre a humanidade do outro, mesmo quando o outro busca aniquilar a humanidade. Embora decerto eu não diga que jamais devamos julgar - os juízos são 
imperativa e igualmente necessários para a vida política, jurídica e pessoal -, acredito que seja importante, ao repensar os termos culturais da ética, lembrarmo-nos de que nem todas as relações éticas são redutíveis a atos de juízo, e que a própria capacidade de julgar pressupõe uma relação prévia entre quem julga e quem é julgado. A capacidade de realizar e justificar juízos morais não esgota a esfera da ética e não coincide com a obrigação ética ou da relacionalidade ética. Além disso, o juízo, por mais importante que seja, não pode ser considerado uma teoria do reconhecimento; com efeito, podemos muito bem julgar o outro sem reconhecê-lo em absoluto ${ }^{13}$.

Com base nessas considerações, assume-se a hipótese de que as circunstâncias que tornam o vínculo terapêutico possível estão profundamente atravessadas pela injunção ética das relações sociais de reconhecimento. Trata-se então de examinar até que ponto as implicações morais do cuidado entram em contradição com expectativas dos trabalhadores da saúde, cuja "competência" é também medida pela capacidade de fazer do relato do paciente o testemunho de uma vida finalmente ajuizável para efeitos prescritivos. A seguir, busca-se dar sequência a raciocínio voltado à elucidação do juízo médico, segundo Paul Ricoeur. Embora assumidamente concebido em relação à "prática médica", admite-se, por analogia, a pertinência de seu desvelamento em relação aos profissionais da saúde em geral.

\section{Três níveis do juízo médico segundo Paul Ricoeur}

A seção anterior abordou a relação entre "justiça" e "reconhecimento" no âmbito de indagação geral sobre a estrutura das relações sociais, remetendo ao problema do vínculo terapêutico como experiência determinada pela expectativa de autorrealização recíproca de pacientes e profissionais de saúde. Essa hipótese de articulação entre fenômenos sugere matriz comum de interpretação a fim de compreender de que modo diferentes domínios normativos são marcados pelo selo da reciprocidade, a partir do qual a norma fundamental da justiça ("a cada qual o que lhe é devido") é efetivamente aplicada.

A tese de que o juízo médico também é normativo não deveria surpreender. O chamado "código hipocrático", malgrado a influência de empirismo ainda subordinado a categorias nosológicas especulativas, já advertia seus adeptos sobre a importância de agir unicamente em nome do "bem" do paciente. Por mais distante de sua origem que hoje pareça essa ideia - de que o vocabulário médico não guarda relação direta com o discurso moral -, ela encontra abrigo em visão cinicamente alheia aos verdadeiros fins da atuação, pois sua história não tem sido outra senão a progressiva transformação de técnicas e procedimentos em torno daquilo que permanece - ou deveria permanecer - como núcleo inconfundível de "autoridade".

Contudo, embora indissociável do discurso moral, convém não presumir que a medicina faça de suas prescrições conjunto de máximas universais abstratas. Mesmo que circunscrito aos enunciados do discurso prático, o juízo médico não está apartado dos sujeitos concretos que o enunciam. Ele só pode ser apreendido com base na investigação do que torna específico seu próprio ordenamento discursivo, particularmente quando se considera o horizonte da relação terapêutica, que costuma revelar seu caráter normativo.

Desvelando essa especificidade, o filósofo Paul Ricoeur ${ }^{1}$ distingue três níveis de juízo médico que definem os requisitos práticos da relação terapêutica. No primeiro, "prudencial", a faculdade de julgar é aplicada a situações singulares em que um paciente individual está situado numa relação interpessoal com um médico individual ${ }^{14}$. No segundo, o "deontológico", os juízos assumem a função de normas que transcendem de diferentes maneiras a singularidade da relação entre tal paciente e tal médico ${ }^{15}$. Finalmente, o terceiro nível, denominado "reflexivo", refere-se à tentativa de legitimação dos juízos prudenciais e deontológicos de primeiro e segundo níveis ${ }^{16}$. Essas diferentes instâncias, em conjunto, constroem a representação de uma medicina voltada a elucidar sua ínsita moralidade, implicando médico e paciente, reciprocamente, perante suas expectativas.

O nível prudencial, ponto de partida de Ricoeur ${ }^{1}$, refere-se ao que costuma ser chamado de "pacto de tratamento". De acordo com o autor, é aí que originalmente se inscreve a estrutura da relação médico-paciente. Essa origem não é outra senão o próprio sofrimento humano, cuja natureza singular (ninguém é capaz de sofrer o sofrimento do outro) explicaria por que motivo os juízos do nível prudencial são o primeiro contato com aquilo que define moralmente tal relação.

Ao médico se dirige apelo sobretudo de solicitude, que o condiciona a considerar as particularidades do caso em questão conforme vai se desenhando no relato subjetivo de quem sofre. Como o próprio autor alerta, isso não significa ignorar a importância de saberes técnicos e científicos, mas dotá-los de sentido capaz de orientar o ato médico na busca de resposta - esta, sim, inevitável e decisiva - para a experiência do sofrimento. Como aponta Ricoeur: 
Na base dos juízos prudenciais encontra-se, pois, a estrutura relacional do ato médico: o desejo de ser libertado do fardo do sofrimento e a esperança de ser curado constituem a motivação principal da relação social que faz da medicina uma prática do tipo particular cuja instituição se perde na noite dos tempos ${ }^{12}$.

Não obstante, reconhecer o "pacto de tratamento" como determinado pelas circunstâncias do caso concreto ainda não é suficiente para distinguir cabalmente sua dinâmica enquanto processo interativo. Faltaria, segundo o autor, elemento capaz de caracterizá-lo precisamente como exercício interpessoal de pactuação, de modo que não haveria mais distância significativa, em termos antropológicos, entre o paciente e o agente do tratamento. Mas que elemento pode ser esse? E em que medida se deveria compreendê-lo também como capítulo específico das circunstâncias que constituem a particularidade do caso?

Antes de responder a esses questionamentos, é útil recordar, ainda que brevemente, algumas ideias centrais da teoria social de Axel Honneth ${ }^{9}$. Pensa-se aqui, especificamente, na tripartição proposta pelo autor entre esferas de reconhecimento, delineando as condições intersubjetivas de autorrealização dos indivíduos: confiança (relações afetivas), respeito (relações jurídicas) e estima social (relações solidárias).

A primeira dessas esferas refere-se exatamente à capacidade das pessoas de estabelecer laços entre si. É nela, portanto, que se configuram relações que, como a terapêutica, implicam as partes reciprocamente em regime de reconhecimento afetivo cujo êxito se expressa na confiança mútua. Eis porque é fácil concordar com as palavras de Ricoeur:

É o pacto de confidencialidade que compromete mutuamente um paciente com um médico. Nesse nivel prudencial, ainda não falaremos de contrato e de sigilo médico, mas pacto de tratamento baseado na confiança. Ora, esse pacto conclui um processo original. No início, um fosso e mesmo uma dissimetria notável separam os dois protagonistas: de um lado, aquele que sabe e sabe fazer, do outro, aquele que sofre. Esse fosso é coberto, e as condições iniciais se tornam mais uniformes por meio de uma série de medidas que parte dos dois polos da relação. O paciente (...) "traz para a linguagem" seu sofrimento, pronunciando-o como queixa, o que comporta um componente descritivo (tal sintoma...) e um componente narrativo (um indivíduo em tais e tais histórias); por sua vez, a queixa especifica-se em pedido: pedido de... (cura equem sabe? - saúde e - por que não? - no plano de fundo, imortalidade) e pedido a... dirigido como apelo a tal médico. Sobre esse pedido se enxerta a promessa de observar o protocolo do tratamento proposto, desde que admitido ${ }^{17}$.

Não é que o médico deva ser visto como parte do círculo afetivo primário (amigos, parentes e amantes) do paciente; porém, como alguém profissionalmente envolvido (estar comprometido é outra coisa) com a esperança que move os indivíduos que o procuram, ele termina por ocupar lugar de enorme relevo. Em outras palavras, trata-se de fenômeno inerente ao próprio exercício prático da medicina, posicionando o profissional em relação sem a qual seria impossível determinar, entre a formulação do diagnóstico e o pronunciamento da prescrição, a prudência do julgamento. Do ponto de vista clínico, é somente pelo pacto de tratamento que o médico sabe o que deve ou não fazer, dividindo com o paciente - ao mesmo tempo único e singular em seu sofrimento - a responsabilidade de ponderar riscos e benefícios de se seguir ou não determinado tratamento.

Com efeito, pode-se questionar até que ponto esse primeiro enquadramento hermenêutico do ato médico não idealiza a relação médico-paciente, sobretudo quando se considera o predomínio do paradigma biomédico, em que o corpo, tomado como universal, redutivel à materialidade físico-química, se apresenta como uma maquinaria complexa cuja fisiologia se encontra em seu interior ${ }^{18}$. Em tais circunstâncias, a eficácia do ato médico não estaria mais tão sujeita à avaliação conjunta com o paciente, mas subordinada a parâmetros externos, reduzida a propriedades anátomo-fisiológicas que tornam a prática cada vez mais objetificável. Trata-se, outrossim, de tensionamento entre a medicina como arte (discurso prático) e a medicina como ciência (discurso teórico), em que o risco é o primado absoluto da racionalidade técnico-científica.

Embora não seja o propósito deste ensaio estabelecer, em toda sua amplitude, uma crítica à racionalidade médica moderna, cabe destacar que essa é preocupação sistemática entre os que interpelam a medicina tal como atualmente praticada. Nesse contexto, mesmo que se registrem modelos alternativos em curso, convém ter clareza do tamanho dos desafios, localizados no âmbito de uma relação específica de poder ${ }^{19}$. A assimetria constitutiva entre médico (aquele que sabe) e paciente (aquele que sofre) conduz frequentemente à comunicação heterônoma, cuja lógica leva, quando não ao mais vulgar paternalismo, a justificativas capazes 
de sancionar, aos olhos da comunidade médica, medidas abusivas e autoritárias.

É contra potenciais abusos ou excessos que se deve passar do nível prudencial ao nível deontológico do juízo médico. Em termos ricoeurianos, tal passagem é definida por três razões que, a despeito de sua articulação, conferem, cada uma, significado particular para a ética em relação tanto aos direitos individuais do paciente quanto aos compromissos públicos do médico.

A primeira delas, e a mais óbvia, diz respeito ao dever do profissional de não agir com negligência ou indiferença, pois isso prejudicaria a relação fundada na confiança mútua. Já a segunda razão decorre da já mencionada influência da biomedicina, que tende à objetivação e reificação do corpo humano ${ }^{20}$. Como exposto, trata-se de preocupação fundamental com o exercício do poder médico, que levanta a necessidade de pensar formas eticamente apropriadas de limitá-lo. Por fim, a terceira razão diz respeito à saúde pública, cujos interesses demandam criar esfera de proteção específica que, sem descuidar da defesa dos direitos individuais do paciente, oriente o Estado no processo de formular e implementar ações para prevenir danos ao bem-estar da população.

É com base em todas essas razões que o juízo médico deve prestar contas também a conjunto de normas ligadas, em última instância, às múltiplas funções desempenhadas pela medicina moderna, atrelada aos saberes técnicos e científicos ao mesmo tempo que destinada a findar o sofrimento individual e justificar-se publicamente. Assim, o nível deontológico não se consagra ao culto do "dever pelo dever"; trata de instância fundamental da ética médica pela qual se espera viabilizar relação pautada no equilíbrio entre meios e fins que venham a se interpor - ou mesmo que se sobreponham - à interação médico-paciente. Também aqui, e de forma mais sistemática, Ricoeur fala em três funções distintas, cada qual enraizada em diferentes aspectos morais que fazem da prática médica exercício igualmente pragmático de coordenação de interesses em conflito.

$O$ trecho a seguir retrata com precisão a natureza da primeira dessas funções, que visaria universalizar preceitos pertinentes ao pacto de tratamento que interliga paciente e médico (...). Enquanto o pacto de confiança e a promessa de honrar esse pacto constituem o núcleo ético da relação que liga um médico a um paciente, o momento deontológico do juízo é constituído pela elevação desse pacto de confiança ao nível da norma. O que se afirma é essencialmente o caráter universal da norma: esta liga todo médico a todo paciente, portanto qualquer um que entre na relação de tratamento. Mais profundamente ainda, não é por acaso que a norma se reveste da forma de interdição, a de violar o sigilo médico. No nível prudencial, o que não passava de preceito de confidencialidade conservava as características de uma afinidade a ligar duas pessoas de maneira eletiva; nesse sentido, o preceito podia ainda ser atribuído à virtude da amizade. Na forma de interdito, a norma exclui terceiros, situando o compromisso singular no âmbito da regra de justiça, e não mais dos preceitos de amizade. O pacto de tratamento, do qual falamos no plano prudencial, pode agora ser expresso no vocabulário das relações contratuais. Certamente há exceções por considerar (...), mas elas mesmas devem seguir uma regra: não há exceção sem uma regra para a exceção à regra ${ }^{21}$.

Não menos importante que a primeira, a segunda função do juízo deontológico está ligada à conexão necessária entre a ética médica e demais exigências que conformam o discurso prático, de modo a fazer da universalização dos preceitos um mesmo e único corpo normativo de regras hierarquizadas e coerentes entre si. Além disso, refere-se também à exigência de regular a interação médico-paciente perante conjunto maior de relações e obrigações profissionais que a situam, política e juridicamente, no espaço de determinada ordem social. Em outro significativo trecho voltado ao assunto, verifica-se como Ricoeur aborda essa função:

Uma vez que a norma que rege o sigilo médico faz parte de um código profissional, (...) ela deve estar correlacionada com todas as outras normas que regem o corpo médico dentro de dado corpo político. Tal código deontológico funciona como subsistema dentro do campo mais vasto da ética médica (...). Assim, às normas que definem o sigilo médico correspondem normas que regem os direitos dos pacientes a serem informados sobre seu estado de saúde. A questão da verdade compartilhada vem assim equilibrar a questão do sigilo médico, que obriga apenas o médico. Segredo de um lado, verdade do outro (...). Assim são postas em paralelo as duas normas que constituem a unidade do contrato situado no centro da deontologia, da mesma maneira que a confiança recíproca constituía a pressuposição prudencial principal do pacto de tratamento. Aqui também foi preciso incorporar restrições ao código, em vista da capacidade do doente para compreender, aceitar, interiorizar e, se podemos dizer, compartilhar a informação com o médico que o trata. A descoberta da verdade, principalmente se ela significar sentença de morte, equivale a uma prova iniciática, cujos episódios traumáticos afetam a compreensão que se tem de si mesmo e o conjunto das relações 
com outrem. É o horizonte vital em sua integridade que sofre um abalo. Essa ligação demonstrada pelo código entre o segredo profissional e o direito à verdade possibilita atribuir aos códigos de deontologia uma função bem peculiar na arquitetura do juízo deontológico, a saber, o papel de ponte entre os níveis deontológico e prudencial do juízo médico e de sua ética ${ }^{22}$.

É nessa mesma arquitetura que se insinua, por fim, a terceira função do nível deontológico atribuída ao juízo médico. Segundo o autor, trata-se do papel indispensável de arbitrar conflitos surgidos na fronteira da prática médica de orientação "humanista"23. Nesse caso, Ricoeur fala em duas frentes principais em que se dão tais conflitos. A primeira consiste no encontro entre a ética médica orientada para a clínica (curar a doença e cuidar do doente) e a ética médica orientada para a pesquisa (produzir evidências científicas). Como dito, aqui o problema se refere ao tensionamento entre a chamada "arte médica" e as ciências biomédicas, cuja causa parece ser o aumento da pressão das técnicas objetivadoras sobre a medicina praticada como arte ${ }^{24}$.

Já a segunda frente diz respeito a preocupação mais direta com a saúde pública. Aqui, em particular, transparece outro tipo de tensionamento, entre o dever de zelar pela dignidade pessoal do paciente e encarar a saúde como fenômeno social. Nas palavras de Ricoeur:

Ora, um conflito latente tende a opor a preocupação com a pessoa e sua dignidade e a preocupação com a saúde como fenômeno social. Esse é o tipo de conflito que um código como o Código francês de deontologia médica, se não tende a dissimular, tende pelo menos a minimizar. Assim, seu artigo 2o reza que "o médico, a serviço do indivíduo e da saúde pública, exerce sua missão no respeito à vida humana, à pessoa e à sua dignidade". Esse artigo é um modelo de solução de compromisso. A ênfase é posta na pessoa e em sua dignidade; mas a vida humana também pode ser entendida no sentido de maior extensão das populações e até do gênero humano em seu todo. Essa consideração da saúde pública afeta todas as regras mencionadas antes, para começar a do sigilo médico. Cabe saber, por exemplo, se um médico tem o dever de exigir do paciente que este informe seu parceiro sexual de sua condição de soropositivo, ou mesmo se não é preciso fazer uma triagem sistemática, que não pode deixar de afetar a prática do sigilo médico. (...) Depende das instâncias legislativas de uma sociedade (Parlamento em alguns países, instituições judiciárias superiores em outros) prescrever os deveres de cada um e definir as exceções à regra.
Mas o dever da verdade devida ao paciente também é afetado, uma vez que são numerosos os terceiros implicados no tratamento. (...) Esse encargo administrativo assumido pela saúde pública não afeta menos o terceiro pilar da ética normativa que, ao lado do sigilo médico e do direito à verdade, é constituído pelo consentimento esclarecido ${ }^{25}$.

Até aqui, é possível que tenha ficado a impressão de que os diferentes níveis do juízo médico traduzem momentos estanques na relação terapêutica, algo como um "passo a passo" para o médico seguir em cada etapa do seu encontro com o paciente. Todavia, esses níveis não se relacionam dessa forma. Na perspectiva defendida por Ricoeur ${ }^{1}$, a passagem de um para o outro ocorre (ou deveria ocorrer) de modo articulado.

É no primeiro nível, não por acaso chamado "prudencial", que convergem todas as normas do nível deontológico (desde que devidamente conhecidas e respeitadas, é claro), distinguindo-se deste justamente em virtude da transcendência que tais normas devem assumir em relação a situações singulares que implicam mutuamente médico e paciente. $O$ juízo médico, nesse sentido, assemelha-se a estrutura normativa como outra qualquer. No entanto, como só se realiza enquanto ato situado, pressupõe fonte de julgamento capaz de considerar as normas não mais apenas em função de sua coerência interna ou adequação legal, mas em nome também de sua legitimidade.

A esse nível de juízo Ricoeur ${ }^{1}$ chamará precisamente de "reflexivo". Trata-se para o autor de momento em que o juízo médico encontra seu verdadeiro vértice dialético, confrontando-se decisivamente com a finalidade (telos) que o põe em permanente movimento, desde os primeiros contatos travados com determinado paciente até a definição do pacto de tratamento. Nesse ponto, tudo parece depender de quanto o conceito de saúde se articula a crenças morais que perfazem a totalidade do julgamento, inclusive aquelas voltadas a expandir relações de reconhecimento recíproco que, passando pela mútua confiança, culminam no respeito e na solidariedade.

Conforme Ricoeur, o que está em jogo, em última instância, é a própria noção de saúde, seja ela privada ou pública. Ora, esta não é separável daquilo que pensamos - ou tentamos não pensar sobre as relações entre vida e morte, nascimento $e$ sofrimento, sexualidade e identidade, nós mesmos e os outros. Aqui, é transposto um limiar no qual a deontologia se enxerta numa antropologia filosófica, que não poderia escapar ao pluralismo das convicções nas sociedades democráticas ${ }^{26}$. 
Dado seu caráter limítrofe com a própria ordem social em que se inscreve a experiência moral do vínculo terapêutico, o nível reflexivo é o ponto de contato entre os dois primeiros níveis do juízo e o tipo de interação médico-paciente que desejamos. Em se tratando de sociedades democráticas, a questão é saber até onde a prática médica deve ir além da mera anamnese clínica, reconhecendo, no corpo de cada paciente, o indivíduo ali instalado, com sonhos, direitos e desejos indissociáveis do processo terapêutico. Daí a importância de perspectiva ética que, atenta às demandas por reconhecimento, retome, na hipótese de conflitos, o significado fundamental da busca por justiça que é a motivação básica dos agentes sociais.

\section{Considerações finais}

A relação entre "justiça" e "saúde", no que se refere à estrutura do vínculo terapêutico, corrobora a percepção de que estamos imersos em trama moral que nos liga irremediavelmente uns aos outros, em busca sobretudo de "tratamento justo". Desse modo, refletir sobre o cuidado como esfera de "competência técnica" significa também pensar a ética profissional de modo a acolher e amplificar lutas de afirmação de populações historicamente excluídas da consideração pública do Estado. É nesse ponto em particular que se vislumbra o verdadeiro eixo de articulação entre a dimensão política do vínculo terapêutico e o compromisso com o bem-estar individual e coletivo.

\section{Referências}

1. Ricoeur P. O justo: justiça e verdade e outros estudos. São Paulo: WMF Martins Fontes; 2009. v. 2.

2. Blumer H. A sociedade como interação simbólica. In: Coelho MC, organizadora. Estudos sobre interação: textos escolhidos. Rio de Janeiro: EdUERJ; 2013. p. 75-90.

3. Piaget J. O juízo moral na criança. São Paulo: Summus; 1994.

4. Habermas J. Obras escolhidas: ética do discurso. Lisboa: Edições 70; 2014. v. 3.

5. Werneck A. Sociologia da moral, agência social e criatividade. In: Werneck A, Oliveira LRC, organizadores. Pensando bem: estudos de sociologia e antropologia da moral. Rio de Janeiro: Casa da Palavra; 2014. p. 25-48.

6. Supiot A. Homo juridicus: ensaio sobre a função antropológica do direito. São Paulo: WMF Martins Fontes; 2007. p. VIII.

7. Fortes PD. A origem do problema da justiça: breve esboço fenomenológico. Pablo Dias Fortes [blog] [Internet]. 27 nov 2017 [acesso 8 jun 2109]. Disponível: https://bit.ly/3baKv2B

8. Goffman E. A representação do eu na vida cotidiana. 20a ed. Petrópolis: Vozes; 2014.

9. Honneth A. Luta por reconhecimento: a gramática moral dos conflitos sociais. $2^{a}$ ed. São Paulo: Editora 34; 2011.

10. Butler J. Relatar a si mesmo: crítica da violência ética. Belo Horizonte: Autêntica; 2015.

11. Mendonça RF. Reconhecimento. In: Avritzer L, Bignotto N, Filgueiras F, Guimarães J, Starling H, organizadores. Dimensões políticas da justiça. Rio de Janeiro: Civilização Brasileira; 2013. p. 117-131.

12. Ricoeur P. Op. cit. p. 223

13. Butler J. Op. cit. p. 64-5.

14. Ricoeur P. Op. cit. p. 221.

15. Ricoeur P. Op. cit. p. 221-2.

16. Ricoeur P. Op. cit. p. 222.

17. Ricoeur P. Op. cit. p. 223-4.

18. Bastos LAM. Corpo e subjetividade na medicina: impasses e paradoxos. Rio de Janeiro: Editora UFRJ; 2006. p. 37.

19. Bastos LAM. Op. cit.

20. Ricoeur P. Op. cit. p. 225.

21. Ricoeur P. Op. cit. p. 227-8.

22. Ricoeur P. Op. cit. p. 228-9.

23. Ricoeur P. Op. cit. p. 229.

24. Ricoeur P. Op. cit. p. 230

25. Ricoeur P. Op. cit. p. 231-2.

26. Ricoeur P. Op. cit. p. 234-5.

Participação dos autores

Pablo Dias Fortes elaborou a primeira versão do artigo com base em capítulo de sua tese de doutorado. Posteriormente, os dois autores se alternaram em revisões do texto até chegarem a esta versão.

\section{Correspondência}

Pablo Dias Fortes - Estrada de Curicica, 2.000, Jacarepaguá CEP 22780-194. Rio de Janeiro/RJ, Brasil.

Pablo Dias Fortes - Doutor - pdiasfortes@gmail.com

(iD) $0000-0002-2022-2626$

Sergio Rego - Doutor - rego@ensp.fiocruz.br

(iD) 0000-0002-0584-3707

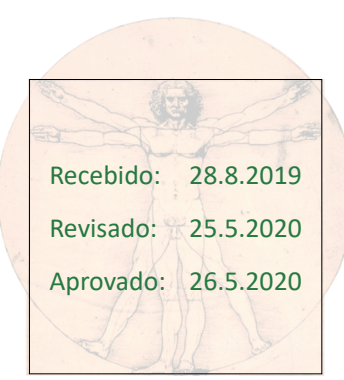

